\title{
Advanced Practice Nurses in Japan: Education and Related Issues
}

\section{Akiko Kondo*}

Graduate School of Nursing, Tokyo Women's Medical University, Tokyo, Japan

\begin{abstract}
Nurse Practitioners (NPs) have proven their abilities and have been authorized to practice in many developed countries. NPs play some independent roles that previously were the roles of physicians. However, NPs have not been introduced in Japan. The main reason is that there is not enough evidence that nurses can practice independently from physicians to change the Medical Practitioners Act. The Japanese version of an NP, which is similar to a Physician Assistant, is under consideration for introduction in Japan. The Japanese version of NPs would be able to conduct specific medical treatments with a "comprehensive order" from a physician.

Certified Nurse Specialists (CNSs) and Certified Nurses (CNs) are Advanced Practice Registered Nurses in Japan. The outcome evaluations of the performance of CNSs have been limited to the descriptive data of case reports. Studies that provide a high level of evidence and evaluate the work and skills of CNSs are necessary so that their abilities can be appreciated. One of the roles of CNSs is research. However, their education emphasizes clinical practice and the time allotted to research in the curriculum is limited. Nursing faculty members at universities are usually very busy providing education and do not have sufficient time to perform research.

To obtain evidence that nurses can work independently, the educational system must allow nursing faculty members at universities to have more time for research and provide the education that would allow CNSs to collaborate with faculty members who perform research. Unfortunately, the fact that there is not enough evidence of nursing ability and this is the key reason of preventing introduction of NPs in Japan is not well known to nurses. It is necessary to tell and educate nurses the necessity of research and to encourage them doing it.
\end{abstract}

Keywords: Nurse practitioner; Certified Nurse Specialists (CNSs); Evidence of practice

\section{Introduction}

Nurse Practitioners (NPs) have proven their abilities and have been authorized to practice in many developed countries. They play an important role in the medical system because of the shortage of medical doctors, particularly in isolated areas. Searching the PubMed (US National Library of Medicine of the National Institutes of Health) database using the key words "nurse practitioner," "outcome," and "comparison" revealed ten articles that compared patient outcomes following treatment by either NPs or medical doctors that were published between 1966 and 2011. Four studies are from the US [1-4], four are from the UK [5-8], one is from Canada [9], and one is from the Netherlands [10]. Five were randomized controlled studies [2,5-7,9,10], three were prospective studies $[3,8]$, and two were retrospective studies $[1,4]$.

NPs play some roles independently that previously were the roles of physicians. For example, New York state law allows NPs to practice with a collaboration agreement that requires a physician to respond when the NP seeks consultation. The collaboration does not require the collaborating physician to be on site and requires only quarterly meetings to review cases selected by the NP and the physician. The state also grants NPs full authority to prescribe medications and to be reimbursed by Medicaid at the same rate as are physicians [2]. In the Netherlands, the NP has been a part of the healthcare system since 2000. NPs have a nursing background and are trained at the Master's level in 'advanced nursing practice', which equips them to make autonomous decisions on disease management and prescribe according to protocols. For example, an NP can provide the standardized care for eczema that was previously offered only by a dermatologist. In addition to disease management, NPs emphasize teaching and counseling [10].

No reports have been published in either English or Japanese that compare the practices and patient outcomes of Japanese NPs and physicians. NPs have not been approved because of several barriers and are still controversial. The reasons for the difficulty in introducing NPs are stated as legal limitations, the historical hierarchy in the medical professions and the lack of regard for NPs as nursing professionals [11]. Are these reasons valid?

The current Japanese laws allow only medical doctors and dentists to diagnose and prescribe. In Japan, Certified Nurse Specialists (CNSs) and Certified Nurses (CNs) were institutionally recognized as Advanced Practice Nurses (APNs) in 1996 because of the trend toward specialization in nursing. They are specialized/certified nurses in an area but are not allowed to practice any of the roles of medical doctors. In this article, the author describes the efforts that have been made, the existing barriers, the controversy over introducing NPs into medical practices, and the role and education of CNSs and CNs in Japan.

\section{Efforts to Expand Nurses' Roles and the Barriers to Introducing NPs in Japan}

The Japanese Association of Nursing Programs in Universities (JANPU) and the Japanese Nursing Association (JNA) hope to introduce NPs in Japan. Physicians also would like to introduce NPs to decrease their workload. However, there is not enough evidence that nurses can practice independently. Some physicians have fear for the safety of the patients by delegating some of their roles/tasks to nurses. Therefore, Kangoshi Tokuteinouryoku Ninsho Seido, who can practice specific medical procedures from physicians' comprehensive order similar to physician assistant, is under consideration of introduction.

*Corresponding author: Akiko Kondo, RN, PhD, School of Nursing, Graduate School of Nursing, Tokyo Women's Medical University, Tokyo, Japan, Tel: +81-3 3357-4804 (ext.6267); Fax: +81-20-4663-5779; E-mail: kondo.akiko@twmu.ac.jp

Received January 13, 2013; Accepted January 18, 2013; Published January 21 2013

Citation: Kondo A (2013) Advanced Practice Nurses in Japan: Education and Related Issues. J Nurs Care S5: 004. doi: 10.4172/2167-1168.S5-004

Copyright: (C) 2013 Kondo A. This is an open-access article distributed under the terms of the Creative Commons Attribution License, which permits unrestricted use, distribution, and reproduction in any medium, provided the original author and source are credited. 
However, it is not what JANPU and JNA had desired. It is necessary for nurses to perform more research with high level of evidence to prove their ability in order to introduce NPs. Unfortunately, the fact that there is not enough evidence of nursing ability and this is the key reason of preventing introduction of NP in Japan is not well known to nurses. It is necessary to tell and educate nurses the necessity of research and encourage doing it.

The JANPU drafted a Japanese version of Core Competencies for APNs based on the Core Competencies for NPs that were developed in the US [12] and confirmed their validity by the a survey of active Japanese CNSs in 2008 [13]. They declared that APNs, who have more advanced knowledge and skills than CNSs, are needed because the current regulations prevent CNSs from treating various current health needs, such as mental problems in complex human relationships and changing health priorities due to the decreasing birthrate and the aging population. They also declared the necessity of exploring the education curriculum for APNs using the Japanese version of Core Competencies for APNs. It is believed that the need for APNs is high because of the shortage of physicians, especially in isolated areas. There is also a need for nurse anesthesiologists [13].

In 2008, the Science Council of Japan, which is mainly composed of physicians, also requested that some medical procedures that only physicians are currently allowed to perform be delegated to other medical professionals, such as nurses who are educated properly and have sufficient knowledge and skills. Otherwise, it will be difficult to respond to the medical needs and to maintain and improve the quality and efficiency of medical care [14]. Emergency medical technicians have been allowed to perform the 3 following medical procedures since July 2012: 1) measuring blood sugar and injecting a glucose solution in cases of a low-glucose-induced stroke, 2) administering beta-adrenergic stimulants for severe asthma, and 3) inserting an intravenous line and administering a transfusion to prevent a cardiopulmonary arrest [15]. Some surgeons strongly appealed the necessity of NPs/PAs (physician assistants) to improve the unfavorable working environment of surgeons [16]. Ishida et al. [17] reported that more than $80 \%$ of responding physicians considered NPs' education necessary $(n=230)$. However, approximately $40 \%$ of medical doctors oppose delegating some of their roles/tasks to nurses because they fear for the safety of the patients [18].

APNs may be able to improve the Quality of Life of patients by combining care with a cure, not just by expanding the medical procedures they perform. Ohta [19] reported that collaboration and role-sharing between nurses and physicians appeared to improve the Quality of Life of patients. However, this study collected opinions and impressions from physicians and nurses in 53 cases and did not scientifically evaluate the outcomes of role-sharing. In this study, the head nurses were more afraid of nurses performing medical procedures than were the head physicians (heads of hospitals). Several studies have attempted to provide evidence of nursing care in order to be approved of official payment system for nursing services [20,21]. However, these studies did not have control groups, the sample size was small, and the quality of the evidence was low.

An APN is expected to have autonomy from medical doctors, that is, to make independent judgments to perform medical procedures. The Ministry of Health Labor and Welfare reported in 2010 on the necessity of expanding opportunities for nurses to make independent judgments and expanding the range of procedures that nurses can perform with a "comprehensive order" from a physician [22]. To do this, it was necessary to clarify meaning of a "comprehensive order" from a physician. The Act on Public Health Nurses, Midwives and Nurses had not clarified the conditions under which a "comprehensive order" is required. Therefore, it is necessary to specify the conditions for the use of "comprehensive order" from a medical doctor according to the nurses' abilities. For example, the range of patients and the conditions that nurses can treat, the range of orders that nurses can understand, and a follow up system for the cases when a patient's condition exceeds the nurses' range should be established [22].

The Changing Medical Practitioners Act was indispensable in allowing nurses to perform some medical procedures autonomously, but it has not been changed. Unfortunately, there is not enough evidence that nurses' practice improves the patients' Quality of Life and/or that nurses have the ability to make independent judgments to keep patients safe. The definition of an APN, the abilities and education of APNs and a system for certifying APNs have not been clarified [11].

Nevertheless, several universities started educating the Japanese version of NPs ("Tokuteikangoshi", which is not a formal name but rather is a tentative name) in a Masters' program in 2008, and the graduates have already started working, mainly in hospitals. However, the profession is neither mentioned in the declaration of the JANPU [13] nor has it been legally recognized. The Ministry of Health Labor and Welfare declared in 2011 that institutionalization of the Tokuteikangoshi would occur in the 2013 fiscal year, but that appears to be unlikely. The main reason is that the Japan Medical Association opposes introducing the Tokuteikangoshi [23]. The Japan Medical Association is mainly composed of physicians who own small private clinics. They allow nurses to perform some medical procedures even though this is not legal because there are a small number of physician(s) in a clinic. When the Tokuteikangoshi are introduced and the law is changed to allow only the Tokuteikangoshi, or the highly educated nurses, to perform certain medical procedures, other nurses, who used to perform them illegally, will not be able to do so anymore. In that situation, the small clinic would have difficulty in functioning. Therefore, it is necessary to thoroughly educate nurses to perform specific medical procedures (Kangoshi Tokuteinouryoku Ninsho Seido: the system of approving nurses to perform specific medical procedures).

The Ministry of Health, Labor and Welfare is considering introducing the Japanese version of NPs/PAs, called Kangoshi Tokuteinouryoku Ninsho Seido, but they would not be similar to NPs in the US but rather would function more like PAs. They can perform specific medical treatments with a "comprehensive order" from a physician, and their tasks can be performed without knowledge of nursing. Therefore, the JANPU is opposed to introducing Kangoshi Tokuteinouryoku Ninsho Seido because the Japanese versions of NPs/PAs only assist a physician upon the physician's order. NPs have not been introduced into Japan because of controversy and a lack of evidence of their ability to work independently. Showing the evidence of nurses' ability is imperative to introduce genuine NPs in Japan.

\section{Description of Certified Nurse Specialists in Japan}

In Japan, a CNS is defined as a nurse who has been approved as having "excellent nursing practice ability" in a specific area by passing a JNA examination after completing a certified educational program (Master's Degree) in that area. Following graduation, at least six months of clinical practice with several case reports and various educational activities in the specialty are required, and then the candidates must pass the JNA's CNS examination in their chosen area of specialization. They can then practice as board-certified CNSs. They are expected to provide effective high-quality nursing care and have the special knowledge and skills to care for persons, families and group members who have complex and difficult problems [24]. CNSs have responsibilities in 
the following six areas: practice, consultation, coordination, ethical coordination, education and research. The JNA regulations define the six roles of CNSs as follows [25]:

1. Practice: Provide excellent specialized nursing care to persons, families and group members

2. Consultation: Have consultations with care providers including nurses in the area of specialty

3. Coordination: Coordinate multidisciplinary health and welfare occupational staff so that the necessary care is seamlessly provided in the area of specialty

4. Ethical Coordination: Solve ethical problems and dilemmas to advocate for the rights of persons, families and groups in the area of specialty

5. Education: Educate nurses so that they can improve their quality of care in the area of specialty

6. Research: Research to improve and develop nursing knowledge and skills in the area of specialty

As of November 3 in 2012, 795 CNS are registered [26] in ten specific areas of medicine (Table 1). The areas include Cancer Nursing, Chronic Care Nursing, Women's Health Nursing, Child Health Nursing, Gerontological Nursing, Psychiatric Mental Health Nursing, Family Health Nursing, Infection Control Nursing, Community Health Nursing, and Critical Care Nursing. Home Care Nursing will be certified in 2012, and educational programs for Disaster Nursing and Genetic Nursing will begin in 2013. The number of CNSs in Cancer Nursing is the highest, and Psychiatric Mental Health Nursing is the next largest discipline.

There are 195 programs in 76 universities in Japan offering CNS courses as of 2012 (Table 2). Certification is valid for five years from the date of certification. CNSs must renew their certification every five years. The renewal criteria include at least 2000 hours practicing nursing care and 100 points of research projects and educational activities performed with professionals or community members within the previous five years (there are criteria for the points) [25].

\section{Description of Certified Nurses in Japan}

$\mathrm{CNs}$ are defined as nurses who provide high quality nursing care using expert nursing skills and knowledge and expand and improve the quality of nursing care. CNs are also certified by JNA. They attend a 6-month program organized by the JNA but do not obtain a degree. There are three roles of CNs: practice, coach, and consult in each specific area [25].

\begin{tabular}{|l|c|}
\hline Nursing Specialty & Number of CNSs \\
\hline Cancer Nursing & 327 \\
\hline Psychiatric Mental Health Nursing & 116 \\
\hline Critical Care Nursing & 85 \\
\hline Child Health Nursing & 73 \\
\hline Chronic Care Nursing & 63 \\
\hline Gerontological Nursing & 41 \\
\hline Women's Health Nursing & 38 \\
\hline Community Health Nursing & 23 \\
\hline Infection Control Nursing & 15 \\
\hline Family Health Nursing & 14 \\
\hline Total & 795 \\
\hline
\end{tabular}

As of November 3, 2012

Table 1: Specialty area and number of Certified Nurse Specialists (CNSs).

\begin{tabular}{|l|c|}
\hline Nursing Specialty & Number of CNSs \\
\hline Cancer Nursing & 52 \\
\hline Psychiatric Mental Health Nursing & 21 \\
\hline Critical Care Nursing & 17 \\
\hline Child Health Nursing & 23 \\
\hline Chronic Care Nursing & 17 \\
\hline Gerontological Nursing & 24 \\
\hline Women's Health Nursing & 10 \\
\hline Community Health Nursing & 8 \\
\hline Infection Control Nursing & 10 \\
\hline Family Health Nursing & 5 \\
\hline Home Care Nursing & 8 \\
\hline Total & 195 \\
\hline
\end{tabular}

As of November 3, 2012, there are 76 universities that offer CNS courses.

Table 2: Number of Certified Nurse Specialist (CNS) courses.

1) Practice: Provide high quality nursing care to persons, families and groups using expert nursing skills and knowledge

2) Coach: Coach Nurses through nursing practice

3) Consult: Have consultations with care providers including nurses

As of September 28 in 2012, 10,875 CNs are registered in 21 areas $[25,27]$. The areas include Emergency Nursing, Wound Ostomy and Continence Nursing, Intensive Care, Palliative Care, Cancer Chemotherapy Nursing, Cancer Pain Management Nursing, Visiting Nursing, Infection Control, Diabetes Nursing, Infertility Nursing, Neonatal Intensive Care, Dialysis Nursing, Perioperative Nursing, Breast Cancer Nursing, Dysphagia Nursing, Pediatric Emergency Nursing, Dementia Nursing, Stroke Rehabilitation Nursing, Radiation Therapy Nursing, Chronic Respiratory Nursing, and Chronic Heart Failure Nursing.

The number of CNs in Wound Ostomy and Continence Nursing is the highest (1778), and the number of Infection Control CNs (1612) follows. The certification is effective for five years following the date of certification. CNs' have to renew the certification every five years. The renewal criteria includes practicing nursing care at least 2000 hours and having 50 points of self-disciplinary activities such as attendance and presentation at academic conferences and/or journals within the past five years [25].

\section{Educational Program for CNSs}

JANPU accredits the educational programs for CNSs. The standard educational program for CNSs includes 26 credits. Two credits basically include 15 lectures/seminars (per 85 minutes) or 30 seminars/practice sessions (per 85 minutes). Recently, CNSs have been expected to have higher levels of practice because of the super aging of Japanese society and the shortage of medical doctors. Therefore, 38 credit programs were introduced in several courses in 2012, and the number of courses with 38 credits will increase gradually [24].

\section{The 26-credit program}

The criteria of the 26-credit educational program are as follows:

1. A minimum of 26 credits are necessary for graduation, including 6 credits of practicum.

2. Common subjects included (a) Nursing education, (b) Nursing administration, (c) Nursing theory, (d) Nursing research, e) Consultation theory, (f) Nursing ethics, and (g) 
Nursing policy. At least 8 credits should be taken from the common subjects.

3. A specific area's educational program should be undertaken.

4. The quality of education of the practicum should be guaranteed because practicum is quite important to improve the practicing ability of CNSs. Therefore, practicum should include not only practicing nursing care but also including a variety of methods such as having supervision, discussing case studies, and/or having seminar so that CNS will have skills that can improve practicing ability and expand nursing activities socially and systematically [24].

\section{The 38-credit program}

A 38-credit educational program was established in 2011 to enhance advanced nursing practice.

1. Common Subjects B were added: advanced physical assessment, advanced physiology/ pathophysiology, advanced pharmacology (6 credits added).

2. Reinforced specialized areas' educational program (2 credits added).

3. Reinforced practicum (4 credits added).

In addition, there are 2 credits for dissertation as well as a 26 -credit program. In the 26-credit program, actual research activities and a research paper was required. In the 38-credit program, only a literature review or a written research proposal is required. Table 3 shows an example of Cancer Nursing Course credits with 38 credits [24].

\section{Problems to be solved for the CNS Educational Program}

The CNS educational program was begun more than 10 years ago, and the number of educational programs and active CNSs has steadily increased. It is now time to review and improve the educational program to meet the requirements of society. The following problems need to be addressed:

\section{Problems for certification}

It takes time to obtain a position because at least six months of

\begin{tabular}{|c|c|c|}
\hline & Subjects & Credits \\
\hline \multirow{4}{*}{ Common Subjects A } & Nursing theory & 2 \\
\hline & Nursing research & 2 \\
\hline & Nursing ethics & 2 \\
\hline & Consultation theory & 2 \\
\hline \multirow{3}{*}{ Common Subjects B } & Clinical pharmacology & 2 \\
\hline & Physical assessment & 2 \\
\hline & Pathophysiology & 2 \\
\hline \multirow{3}{*}{ Specialized Common Subjects } & Pathophysiology related to cancer nursing & \multirow{11}{*}{$\begin{array}{l}\text { Total } \\
14 \\
\text { credits }\end{array}$} \\
\hline & Nursing theory related to cancer nursing & \\
\hline & Cancer nursing care & \\
\hline \multirow{8}{*}{ Specialized Special Subjects } & Chemotherapy nursing & \\
\hline & Radiation therapy nursing & \\
\hline & Stem cell transplantation nursing & \\
\hline & Cancer rehabilitation nursing & \\
\hline & Pain nursing & \\
\hline & Palliative care & \\
\hline & Terminal care & \\
\hline & Prevention/early detection & \\
\hline Practicum & Practicum & 10 \\
\hline \multicolumn{2}{|l|}{ Total } & 38 \\
\hline
\end{tabular}

Table 3: Certified Nurse Specialist education courses (Cancer Nursing). clinical practice with several case reports and various educational activities in the specialty are required after graduation to qualify for the certification examination.

- The examination is difficult (the examination pass rate is greater than $80 \%)$.

- If graduates have not been certified, they have difficulties obtaining a position, which starts a vicious cycle.

- CNSs will advance after obtaining their positions and gaining experience.

To solve these problems, follow ups from faculty members after graduation are expected, such as having case study meetings, consultations before taking the examination, and support to obtain a position in the work place [24].

\section{Problems of education to become certified}

The educational background and experiences of students are various, and their readiness is not constant.

- The amount of experience prior to entering the program especially affects the effectiveness of education. Students who had less experience need more experience after graduation (at least five years total).

- Many students are full time workers, and it is hard for them to study.

- Although research competence is expected in the work place and students' logical thinking is enhanced by research, it takes a great amount of time and effort to conduct research.

- In addition to education in the specialized area, it is important to learn various skills, such as leadership, communication, logical thinking, critical thinking, and autonomy.

To solve these problems, continuous education programs after graduation should be considered, while certification criteria by the JNA should be minimal [24]. In fact, the JNA coincidentally reduced the criteria of certification to certify a greater number of CNSs in 2012 [28].

\section{Educational problems to be solved}

The following are necessary educational improvements and the strategies to achieve them.

1) Enhancing practicing ability

- Increase the hours of the programs related to diagnosis, treatment and pharmacology (direct care)

- Increase the number of credits of practicum (more cases involved)

- Enhance subspecialty training

2) Clarifying the competency required for graduation (both common and specialized areas)

3) Keeping a balance of guaranteeing the quality and quantity of graduates

4) Keeping a balance of abilities between a specialist and a generalist

5) Keeping a balance of abilities between practice and research

6) Educating educators, keeping the field of practicum, and modifying the district gap 
7) Establishing a system of certification for educators

8) Establishing a follow up system after completion of the CNS program

While there are many problems to be solved, establishing CNS Master's programs in universities will provide a systematic broad and high level of education in leadership skills, communication, logical thinking, and independent critical thinking, which are indispensable for advanced nursing practice. It is necessary to continuously improve the quality of education to take advantage of graduate programs [24]. It is also necessary to evaluate the efficacy of a 38 -credit program. Outcome evaluations of the performance of CNSs have been limited to the descriptive data of case reports [29-32]. Outcome research is indispensable to measure the efficacy of nursing practices and to maintain and improve the quality of nursing care and nursing education. Randomized controlled studies with large samples are necessary to obtain high-quality evidence. However, the nursing faculty members of universities in Japan are usually too busy educating students to perform their research. To obtain evidence of nursing abilities, the educational system must allow nursing faculty members at universities to have more time for research, and CNSs must have the knowledge that would allow them to do research and/or to collaborate with faculty members who perform clinical research.

\section{Conclusions}

NPs have not been introduced in Japan because of the lack of evidence that nurses can practice independently. The Japanese version of an NP/PA is controversial. CNSs and CNs are the Advanced Practice Registered Nurses in Japan. The outcome evaluations of the performance of CNSs are limited to the descriptive data of case reports. The abilities of CNSs have not been well investigated, and evidence of their abilities might not sufficient to convince physicians to change the Medical Practitioners Act. Studies that provide a high level of evidence and that evaluate the work and skills of CNSs are necessary so that their abilities can be proven and admitted. To do research that provides evidence of nursing practices, a system that allows time for research for nursing faculty members at universities and an education that allows CNSs to be able to perform research will be necessary. Unfortunately, the fact that there is not enough evidence of nursing ability and this is the key reason of preventing introduction of NPs in Japan is not well known to nurses. It is necessary to tell and educate nurses the necessity of research and to encourage them doing it.

\section{Acknowledgments}

The author thanks Professor Mieko Tanaka, Dean of the School of Nursing, Tokyo Women's Medical University, for providing many of the references cited in this paper.

\section{References}

1. Wright WL, Romboli JE, DiTulio MA, Wogen J, Belletti DA (2011) Hypertension treatment and control within an independent nurse practitioner setting. Am J Manag Care 17: 58-65.

2. Mundinger MO, Kane RL, Lenz ER, Totten AM, Tsai WY, et al. (2000) Primary care outcomes in patients treated by nurse practitioners or physicians: a randomized trial. JAMA 283: 59-68.

3. Rudy EB, Davidson LJ, Daly B, Clochesy JM, Sereika S, et al. (1998) Care activities and outcomes of patients cared for by acute care nurse practitioners, physician assistants, and resident physicians: a comparison. Am J Crit Care 7: $267-281$.

4. Karlowicz MG, McMurray JL (2000) Comparison of neonatal nurse practitioners' and pediatric residents' care of extremely low-birth-weight infants. Arch Pediatr Adolesc Med 154: 1123-1126.

5. Sandhu H, Dale J, Stallard N, Crouch R, Glucksman E (2009) Emergency nurse practitioners and doctors consulting with patients in an emergency department: a comparison of communication skills and satisfaction. Emerg Med J 26: 400 404

6. Leslie A, Stephenson T (2003) Neonatal transfers by advanced neonatal nurse practitioners and paediatric registrars. Arch Dis Child Fetal Neonatal Ed 88: F509-F512.

7. Moore S, Corner J, Haviland J, Wells M, Salmon E, et al. (2002) Nurse led follow up and conventional medical follow up in management of patients with lung cancer: randomised trial. BMJ 325: 1145

8. Curzio JL, Rubin PC, Kennedy SS, Reid JL (1990) A comparison of the management of hypertensive patients by nurse practitioners compared with conventional hospital care. J Hum Hypertens 4: 665-670.

9. Mitchell-DiCenso A, Guyatt G, Marrin M, Goeree R, Willan A, et al. (1996) A controlled trial of nurse practitioners in neonatal intensive care. Pediatrics 98 1143-1148.

10. Schuttelaar ML, Vermeulen KM, Drukker N, Coenraads PJ (2010) A randomized controlled trial in children with eczema: nurse practitioner vs. dermatologist. $\mathrm{Br}$ J Dermatol 162: 162-170.

11. Minami H, Ohota K, Uchinuno A, Komatsu H, Akiyama H, et al. (2011) For establishing Advance Practice Nurse - declaration from global standard. Science Council of Japan.

12. National Organization of Nurse Practitioner Faculties (NONPF), American Association of Colleges of Nursing (AACN) (2002) Domeins and Core Competencies of Nurse Practitioner Practice. In: Nurse Practitioner Primary Care Competencies in Specialty Areas: Adult, family, Gerontological, Pediatric and Women's Health.

13. Minami Y, Nozawa M, Inoue T, Katada N, Ibe T, et al. (2008) Core Competency of Advanced Practice Nurse-Recognition of current role of current CNS and future issues. In: Nursing Education III - Education of nursing practice ability Japanese Nursing Association, Tokyo.

14. Kirino K, Tanaka S, Nakata T (2008) Request: Achievement of medicine supported by reliability -In order not to collapse medicine.

15. CB news (2012) Emergency medical technicians are allowed to perform 3 specific medicate procedures in certified facilities.

16. Maehara T, Nishida H, Watanabe T, Tominaga R, Tabayashi K (2010) Surgeons' hope: expanding the professional role of co-medical staff and introducing the nurse practitioner/physician assistant and team approach to the healthcare system. Nihon Geka Gakkai Zasshi 111: 209-215.

17. Ishida Y, Hatao M, Fukushima O, Mori M, Isozaki F, et al. (2012) Comparison between cancer specialists and general physicians regarding the education of nurse practitioners in Japan: a postal survey of the Japanese Society of Clinical Oncology. Int J Clin Oncol.

18. Tokuteikangoshi Transfering Navigation (2011) What are oppositions of Tokuteikangoshi?

19. Ohta K (2009) The research about role-sharing and collaboration between physician and nurses. Report of Health and Labor Sciences Research.

20. Usami S, Nozue K, Fukushima Y, Ando S, Tanaka M, et al. (2009) Liaison mental nursing technique to improve mental status of patients who have chronic physical symptoms. EB Nursing 9: 34-42.

21. Ando S, Nozue K, Usami S, Tabaka M, Sato Y, et al. (2009) Telephone consultation by nurses for patients with mental disorder who live in community. EB Nursing 9: 26-32

22. Ministry of Health Labour and Welfare (2010) About acceleration of team approach to health care.

23. Hashimoto K (2012) Japan Medical Association still gave opposition for certifying Tokuteikangoshi.

24. Tanaka M (2010) Education of Clinical Nurse Specialists in Japan. In: Nursing Education IV Quality and Evaluation of Nursing Education. Japan Association of Nursing programs in Universities.

25. Japanese Nursing Association (2012) Certification system of Certified Nurse Specialist / Certified Nurse / Certified Nursing Administrator

26. Japanese Nursing Association (2012) Registered Certified Nurse Specialist.

27. Japanese Nursing Association (2012) Registered Certified Nurse. 
28. Japanese Nursing Association (2012) Information for examination.

29. Ohtsu S, Ogawa A, Miyanari M, Shinagawa Y, Sato K, et al. (2012) Evaluation of Consultation activities of CNS and CN in a hospital. Journal of Japan Nursing Association 42: 155-158

30. Komatsu H (2010) Oncology Certified Nurse Specialist in Japan. Jpn J Clin Oncol 40: 876-880.
31. Shimomura A (2011) Evaluating the consultation by a Certified Nurse Specialist (CNS) in stroke rehabilitation nursing: Consultation on social behavior deficits in patients with higher cortical dysfunction. Journal of the Tsuruma Health Science Society Kanazawa University 34: 77-89.

32. Kaneko A (2010) Evaluation of activities of Certified Nurse Specialists in Psychiatric Mental Health Nursing from questionnaire. The Kyosai Medical Journal 59: 59-64.
This article was originally published in a special issue, Professional Issues and Trends in Nursing in Japan handled by Editor(s). Dr. Akiko Kondo, Tokyo Women's Medical University, Japan 